\title{
Playing the pandemic
}

This issue of the Interactive Entertainment Law Review is unique in that we are going to press during a global pandemic.

Most will agree that we are living in surreal times, a dystopia composed of murky origins, shocking immediacys, and yet unknowable conclusions. Our reality is unfailingly similar to most adventure video games. However, there is a certain monotony that exists as we seemingly grind through the loot boxes of life 24/7 in search of a prize that makes us feel more certain or safe. When you think about it, our current relationship with video games has changed. Where previously we traversed from the real world through the screen into the realm of fantasy, it is now considerably harder to know which fantastically dangerous dystopia of our two conscious worlds is more treacherous or more at risk?

Despite these distortions to our previously accepted version of reality, statistics tell us video games are doing better than ever, whether measured in time spent on them, or by any other measure. ${ }^{1}$ No doubt part of this may be people having unexpected time on their hands. Another explanation may be that video games have always been an escape, and now we simply need to escape more often and more completely, notwithstanding that the world we are escaping to may be eerily similar in its dangers and obstacles to the world we are choosing to escape from.

Perhaps video game players are adjusting better to the travails of the pandemic because for years we were already social distancing, communicating extremely frequently through technology, and being oddly comfortable with both dystopias, as well as scenarios that change wildly and instantaneously. This is perhaps not as crazy as it sounds given that it is consistent with the view that video games have evolutionary impacts on us humans -

1 Just the merest sampling of articles on the subject: James Batchelor, 'NPD US console sales in April up $163 \%$ to $\$ 420 \mathrm{~m}$ - Video games hardware and software generated $\$ 1.5$ billion last month, making it the biggest April on record', gamesindustry.biz (22 May 2020), available at: https://www.gamesindustry.biz/articles/2020-05-22-npd-us-console-sales-in-april-up-163percent-to-usd420m; Sam Desatoff, 'Report: Video game sales increased by $73 \%$ in April, setting new records for the month (NPD Group)', gamedaily.biz (22 May 2020), available at: https://gamedaily.biz/article/1752/ report-video-game-sales-increased-by-74-in-april-setting-new-recordsfor-the-month-npd-group; 'The giants of the video game industry have thrived in the pandemic. Can the success continue?', Washington Post; Stefan Hall, 'How COVID-19 is taking gaming and esports to the next level', weforum.org (15 May 2020), available at: https://www.weforum.org/ agenda/2020/05/covid-19-taking-gaming-and-esports-next-level/; Patrick Shanley, 'Gaming Usage Up 75 Percent Amid Coronavirus Outbreak, Verizon Reports', hollywoodreporter.com (17 March 2020), available at: that we develop physical and psychological $^{2}$ skills that will serve the cause of humanity's survival over the long term. ${ }^{3}$ Which leads to the not wholly unrealistic expectation that the post Covid-19 world will be comprised of more video game players, playing more video games than ever before, and consciously or not, preparing ourselves for future unexpected challenges. If nothing else, video game players are good at complex puzzles, skills that bode well for a post Covid-19-vaccine earth, likely to be more complicated and puzzling than ever before.

However, there is one more thing. ${ }^{4}$ A hopeful yet controversial reality is emergent from our immediate experiences and predicaments. To put it simply, we must appreciate that everything is political. Everyone within and outside the world of video games should now understand that even feigning to be non-political is itself a powerful political statement, almost certainly one favouring a western, white, male oriented self-perpetuating status quo in power structures and economic wealth. A global health pandemic accompanied by a worldwide protest demanding long promised but insidiously denied equality among peoples and genders probably may come well within the comfort range of astute, well informed, and experienced video game players. They are already very comfortable stepping out to join the fight - in the name of digital destiny. They are driven to fight without compromise for what is theirs or should be, usually against a grand, cruel, and seemingly all-powerful foe.

In the game world we know what happens next. Never retreat, never surrender. Video game players battle through the impossible odds to the other side where a new dawn rises. In some way or another that is the narrative of every video game ever played, from puzzles to racers to MMORPGs. The question is how many are

https://www.hollywoodreporter.com/news/gaming-usage-up-75-percent coronavirus-outbreak-verizon-reports-1285140

2 See Darla Read, 'COVID-19: Video games good for mental health during pandemic, says U of S prof, the starphoenix.com (5 May 2020), available at: https://thestarphoenix.com/news/local-news/covid-19-video-gamesgood-for-mental-health-during-pandemic-says-u-of-s-prof.

3 In terms of mostly learning, physical and intelligence skills, this view is perhaps most functionally articulated by Mary Meeker of Kleiner Perkins in her 2017 Recode Conference presentation which can be found at https://youtu.be/UC8GwG6srqs at 9:12.

4 As Steve Jobs famously used to say. See for example Ewan Spence, 'Five Of The Greatest "One More Thing..." Moments From Steve Jobs And Apple', forbes.com (19 October 2013), available at: https://www.forbes.com/sites/ ewanspence/2013/10/19/five-of-the-greatest-one-more-thing-momentsfrom-steve-jobs-and-apple/\#20ea27c87169. 
ready to fight away from the keyboard, controller or mouse?

Will we determinedly choose to play this real-life mutation of our game spaces through to the end, no matter the consequences? Are we now fully in the game? Let's hope so. Because our collective life is a console that cannot be turned off.

We as a Journal express our solidarity with the Black Lives Matter movement and the global protests against systemic racism. We echo our colleagues in their demand to examine structures of racial privilege within the video game industry and related scholarship. ${ }^{5}$

In this issue, Daniel Lintaman's 'Unusual canvasses: resolving copyright infringement through the lens of community customs' explores the relationship between the foregrounds and backgrounds of artistic works, making us think more deeply in a legal way about both the positive and negative spaces that define creativity. Our second article continues the dance of perspectives in Anthony Michael Catton's 'What is mine in Minecraft? Assessing the copyright and ownership of in-game player creations (Part 2)'. From there our travels through the inverse of the ordinarily expected continue in Oliver Brown's 'The author's arsenal: loosening standards for protectability and substantial similarity in video game copyright'. The remainder of our journey traverses from the land of the unexpected to the realm of the somewhat hidden, beginning with Hanna Callens' 'Kidfluencer marketing in the video game industry', continuing through to Rosie Burbidge's 'A lost destiny or world of warcraft? Unlocking the hidden power of designs'. Our final stops are on land, but here too the unexpected is not a stranger as Irina Shurmina guides us through 'Digital advertising: regulations and challenges in Russia' while Ksenia Danshina explains 'The Russian approach to regulating video games: a playthrough'.

Destination found - still COVID bound. We can but wish for health, safety and freedom in a world arching towards equality and justice ...

Dr Gaetano Dimita Professor Jon Festinger Q.C. Dr Marc Mimler
5 Excerpted and slightly adapted from a statement by Arvind Rajagopal at NYU setting out some of the reasons for the 'whiteness' of media studies, whilst calling upon academics to move away from this undeniably racist past. 